miles to the south, and as far east as Caledon Bay on the Gulf of Carpentaria. The increase was so rapid that by 1885 it was estimated that there were six thousand buffaloes on Melville Island and about sixty thousand on the mainland.

The water or Asiatic buffalo, Bubalis buffelus, is a powerful animal, more than five feet high and almost ten feet long. It is heavily built, has short powerful legs with white fetlocks and large hoofs, a short tail and brown hair on an ashy-grey to blackish hide. The immense, hollow and sharply pointed horns may be crescentic in shape or develop into several spirals. The wild herds do not roam far afield from where they were born, their spread through the country in small herds being gradual as their numbers increase. They stay near water, in which they will stand for hours side by side, with only the wide muzzles and horns of their long heads uncovered. The bulls fight for control of a herd of cows in the autumn mating season, and old bulls unable any longer to hold their own with their younger rivals become wandering outcasts of an extremely dangerous nature. A cow bears one calf each year. The bulls will charge a foe threatening the herd.

This buffalo is a native of north-eastern India, where wild ones cause considerable damage to crops. It has a reputation for being the most dangerous animal after the tiger, and is always shot by hunters from an elephant. Hunting began in Australia in 1885, but after 1905 the great and uncontrolled slaughter of the beasts soon depleted the herds perilously and the Government took steps to save them. Permits are now issued for hunters to operate in a defined area. They are allowed to shoot a quota of bulls, but no cows. In recent years between six and eight thousand buffalo skins have been marketed annually for heavy machinery belts and similar uses, at an average price of between $£ 5$ and $£ 6$ per skin.

The hunting of buffaloes in western Arnhem Land is a dangerous and strenuous job, carried out in the dry season. It demands great horsemanship, skilful shooting and endurance above the ordinary. In the past, the ruthless depletion of the herds, the employ. ment of natives who get little reward but disrupted lives, added to its undesirable nature; these defects have now been rectified. As the dingo is the only natural enemy of the buffalo in Australia, the shooting of a specific number each year is essential or the herds would expand beyond the country's resources to sustain them.

\section{MICROWAVE AMPLIFICATION BY STIMULATED EMISSION OF RADIATION}

NEW instrument called the 'maser' (microwave
amplification by stimulated emission of radia-
tion) has been invented by Prof. C. H. 'Townes, of the
Physics Department, Columbia University, for which
the claim is made that it enables time to be measured
with an accuracy of one part in $10^{11}$. The 'clock'
used is an ammonia molecule which radiates an
electric dipole spectrum as a set of lines of about $6 \mathrm{~mm}$.
wave-length and, as used in the instrument, maintains
its frequency to the above order of magnitude. This
would be sufficient to enable it to measure variation
in the rate of rotation of the earth.
According to the details issued by Columbia
University, the instrument consists of a molecular beam of ammonia molecules which are excited in an electric field and then pass into a tuned cavityresonator, where they induce each other to radiate by negative absorption (in effect, giving a form of chain reaction). In this way, all factors causing broadening or displacement of the line emitted are reduced to a minimum. It seems that the method of use is to extract by means of wave-guides the radiation emitted by two 'masers', tuned to different but adjacent frequencies by the ammonia spectrum. When mixed, the beat frequency can then be counted electronically. 'The 'maser' is also claimed by its inventor to be very effective as an amplifier. The signal is fed into the resonant cavity, and a molecular beam, too weak to cause a complete chainreaction, is introduced. The signal controls the rate of emission of the radiation, again by negative absorption, and, it is stated, the system is almost completely free from noise. Thus it would be very useful for amplification at millimetre wave-lengths. A limitation, however, would appear to be that the device is scarcely tunable. The only frequencies available are the half-dozen or so lines of the ammonia molecule, all in the $6-\mathrm{mm}$. region of the spectrum, and the lines of other chemical compounds. It is not stated what sort of a total band may be expected ultimately to be covered by the frequencies of various compounds.

The 'maser' is not the only time-measuring device using microwave spectra of molecules. The alternative method is to use an absorption technique, tuning a conventional oscillator on to exactly the molecular frequency. But Prof. Townes claims that this method is considerably less accurate. As at present built, the 'maser' is a fairly large device, a few cubic feet in volume, but Prof. Townes suggests that this can be considerably reduced. He proposes that, apart from being used as an accurate clock for experimental work on the earth's rotation period, it might also serve as a frequency standard for radio frequencies generally. This would certainly give greater accuracy than the usual quartz crystal, but it is doubtful if this is required, and the method would be less convenient to use, except perhaps in the region of centimetre waves.

\section{MYXOMATOSIS OF RABBITS}

$\mathrm{T}$ HE second report of the Advisory Committee on Myxomatosis* follows fairly soon after the first report (see Nature, 173, 856 ; 1954) and records that this disease, which appeared in Kent, Sussex, Essex and Suffolk in 1953, had, by the end of 1954, spread to every county in Great Britain except Selkirk. It had appeared as far north as the Orkneys, but its spread was most marked in southern England and in Wales, only isolated outbreaks occurring in northern England and Scotland. A map issued with the report shows the extent of the distribution of the disease at the end of 1954. In Europe the disease exists in France, where it has resulted in the virtual disappearance of rabbits over large areas, and in Belgium, Luxembourg and elsewhere. It also exists in Ireland.

In view of reports that symptoms resembling those of myxomatosis have been reported in animals other

* Ministry of Agriculture and Fisheries-Department of Agriculture for Scotland. Myxomatosis: Second Report of the Advisory Com-
mittee on Myxomatosis. Pp. ii $+6+1$ map. (London: H.M.S.O., 1955.) 1s. net. 